\title{
Assessing the role of stress signalling via p38 MAP kinase in the premature senescence of Ataxia Telangiectasia and Werner syndrome fibroblasts
}

\author{
Terence Davis · David Kipling
}

Received: 28 July 2008/Accepted: 18 September 2008/Published online: 1 October 2008

(C) The Author(s) 2008. This article is published with open access at Springerlink.com

\begin{abstract}
The premature ageing Ataxia Telangiectasia (AT) and Werner syndromes (WS) are associated with accelerated cellular ageing. Young WS fibroblasts have an aged appearance and activated p38 MAP kinase, and treatment with the p38 inhibitor SB230580 extends their lifespan to within the normal range. SB203580 also extends the replicative lifespan of normal adult dermal fibroblasts, however, the effect is much reduced when compared to WS cells, suggesting that WS fibroblasts undergo a form of stress-induced premature senescence (SIPS). A small lifespan extension is seen in AT cells, which is not significant compared to normal fibroblasts, and the majority of young AT cells do not have an aged appearance and lack p38 activation, suggesting that the premature ageing does not result from SIPS. The lack of p38 activation is supported by the clinical manifestation, since AT is not associated with inflammatory disease, whereas WS individuals are predisposed to atherosclerosis, type II diabetes and osteoporosis, conditions known to be associated with p38 activation.
\end{abstract}

Keywords c-Jun · HSP27 - Inflammatory disease · JNK · Premature ageing · SB203580 - Stress-induced premature senescence $\cdot$ Therapeutics

T. Davis $(\bowtie) \cdot$ D. Kipling

Department of Pathology, School of Medicine, Cardiff University, Heath Park, Cardiff CF14 4XN, UK

e-mail: davist2@cardiff.ac.uk

\section{Introduction}

Ataxia Telangiectasia (AT) is a multi-system human genetic syndrome caused by mutations in the ATM gene (Savitsky et al. 1995) that results in progressive neurodegenerative dysfunction, a predisposition to cancer, immune deficiency, and genome instability, with a hallmark of onset in early childhood (Crawford 1998). In addition, individuals with AT have features reminiscent of premature ageing, such as grey hair, wrinkled skin, skin atrophy and sclerosis, and AT has been described as a segmental progeroid-like syndrome (Barzilai et al. 2002; Hofer et al. 2005; Rotman and Shiloh 1997; Wood et al. 2001; Wong et al. 2003). At a cellular level, fibroblasts derived from individuals with AT undergo premature replicative senescence, manifested by a shortened in vitro lifespan and a reduced colony forming ability (Elmore and Swift 1976; Hoar 1975; Shiloh et al. 1982; Tchirkov and Lansdorp 2003; Vaziri et al. 1997).

Werner syndrome (WS) is caused by mutations in the WRN gene and affected individuals show the premature onset of several clinical features of old age, including cataracts, skin atrophy, hair-greying and soft tissue calcification, together with age-related diseases such as type II diabetes, atherosclerosis and osteoporosis (Martin et al. 1999). WS is also associated with genomic instability and a high incidence of cancer. The age of diagnosis is often in the early teens as individuals lack the pubertal growth spurt. 
Associated with premature ageing, accelerated cellular replicative senescence is found in WS with over $90 \%$ of WS fibroblast cultures having an in vitro lifespan of $<25$ population doublings (PDs) (Tollefsbol and Cohen 1984).

Replicative senescence in normal human fibroblasts results from the progressive loss of telomeric repeats at the ends of chromosomes due to the inability of the DNA replication machinery to efficiently replicate the $5^{\prime}$ ends of linear chromosomes (Harley et al. 1990). Thus, it is formally possible that the accelerated senescence seen in AT and WS cells is due to accelerated telomere erosion or a change in the threshold at which telomeres are sensed by the cell as 'critically short' and thus trigger senescence. Initial evidence suggested that telomere erosion rates were elevated in WS cells (Schulz et al. 1996), however, more recent data has shown that the accelerated cellular senescence seen in WS is not associated with an increased rate of telomere erosion per cell division (Baird et al. 2004). AT fibroblasts also appear to have an elevated rate of telomere erosion compared with normal cells (Tchirkov and Lansdorp 2003; Vaziri et al. 1997), and telomeres were found to be shorter in fibroblasts and peripheral blood lymphocytes isolated from AT compared to aged-matched normal individuals (Metcalfe et al. 1996; Pandita et al. 1995; Vaziri et al. 1997; Xia et al. 1996). Treatment of AT cells with a specific anti-oxidant appeared to reduce the telomere erosion rate considerably, however, this was accompanied by only a small increase in replicative lifespan (Tchirkov and Lansdorp 2003). These data, taken together, seem to suggest that in AT cells there is an increased rate of telomere shortening, but this may not lead to the reduced replicative cellular lifespan.

The AT and WS fibroblasts early in their replicative lifespan are reported to show an altered, enlarged, cellular morphology due to the presence of extensive networks of F-actin stress-fibres (Davis et al. 2005; McKinnon and Burgoyne 1985), and resemble normal fibroblasts that have undergone stress-induced premature senescence (SIPS) as a result of oncogenic ras expression or arsenite treatment (Deng et al. 2004; Guay et al. 1997; Huot et al. 1997; Wang et al. 2002). These features of SIPS can result from activation of the stress-associated $\mathrm{p} 38 \alpha$ MAP kinase as the use of the p38 selective inhibitor SB203580 prevents ras-induced senescence in human
BJ fibroblasts (Deng et al. 2004; Wang et al. 2002). Activation of p38 leads to the stabilisation of the cyclin-dependent kinase inhibitor $\mathrm{p} 21^{\mathrm{WAF} 1}$ and subsequent cell cycle arrest, and also leads to the phosphorylation of the small heat shock protein HSP27 resulting in stress fibre formation (Deng et al. 2004; Haq et al. 2002; Kim et al. 2002).

Recent work has shown that WS fibroblasts have a normal lifespan and cellular morphology when treated with the p38 inhibitor SB203580; in effect SB203580 prevents the accelerated ageing that is a hallmark of WS cells (Davis et al. 2005). Thus, the accelerated ageing is thought to be due to SIPS, and the p38 signalling pathway is activated in cultures of young WS cells. The SIPS seen in WS cells may be driven by replicative stress as the WRNp is a DNA helicase associated with the replication fork, and a high degree of replication fork stalling is seen in WS cells (Rodriguez-Lopez et al. 2002; Pichierri and Franchitto 2004; Davis and Kipling 2007).

ATM, the protein mutated in AT, is the primary checkpoint kinase in response to DNA damage (Kastan and Lim 2000; Pandita 2002). It functions as a part of a large multi-protein complex that includes WRN, and is thought play an important role in the cellular response to replicative stress (Pichierri and Franchitto 2004). These observations, and the recent report that WRN cooperates with ATM to implement the intra-S phase checkpoint in cells with collapsed replication forks (Cheng et al. 2008), suggests that the premature senescence seen in AT cells may occur via a similar pathway to that in WS cells. Thus, the reported similarities between young AT cells, WS cells, and normal cells that have undergone SIPS, and the observation that hTERTimmortalised AT fibroblasts are able to undergo SIPS via p38 activation in response to ionising radiation despite the lack of ATM (Naka et al. 2004), suggest the possible involvement of p38 and SIPS in the accelerated ageing of AT fibroblasts.

The genome instability and increased pro-oxidant state seen in AT provide a plausible trigger to activate stress-signalling in AT cells and a possible involvement for $\mathrm{p} 38$ in inducing the shortened replicative lifespan and altered cellular morphology (Ball and Xiao 2005; Barzilai et al. 2002). We therefore tested the role of p38-transduced stress signalling in AT using SB203580, a cytokine-suppressive anti-inflammatory drug whose major (but not sole) inhibitory 
target is p38 (Iwasa et al. 2003), together with primary fibroblasts derived from dermal biopsies of three separate AT patients. Although SB203580 was effective in extending the replicative lifespan of AT cells, the degree of lifespan extension was not significantly more than that seen for normal adult dermal fibroblasts, and it appears that, unlike in WS, the accelerated senescence seen in AT fibroblasts is not due to $\mathrm{p} 38$-induced SIPS.

\section{Materials and methods}

Cells and cell culture

Primary AT (GM05823, AG03058, and AG04405), WS (AG05229, AG03141, and AG12795) and normal adult dermal (AG04552, AG09603, AG11020, and AG13152) fibroblasts derived from biopsies of human tissue were obtained from the Coriell Cell Repository (Camden, NJ, USA). For added clarity, when referring to the individual cell strains in this paper a suffix (AT, WT or WS) has been added to the designating code for Ataxia, wild-type, or Werner cells, respectively. HCA2 cells that have been immortalised by the ectopic expression of human telomerase (herein called HCA2.trt cells) have been described previously (Davis et al. 2006). All cells were grown in Dulbecco's modified Eagle medium (DMEM) supplemented with $10 \%$ foetal calf serum in an atmosphere containing $5 \% \mathrm{CO}_{2}$, and passaged every 4-5 days as described previously (Davis et al. 2003). PDs were calculated according to the formula: PDs $=\log _{2}\left(N_{\mathrm{t}} / N_{\mathrm{o}}\right)$, where $N_{\mathrm{t}}$ is number of cells counted and $N_{\mathrm{o}}$ is number of cells seeded. For experiments using p38 MAP kinase inhibitors, the medium was supplemented with $10 \mu \mathrm{M}$ SB203580 (Tocris Chemical Co. Bristol, UK) in DMSO, with the medium changed daily. For controls, an equivalent volume of DMSO was added to the medium. SB203580 was used at $10 \mu \mathrm{M}$, a concentration used routinely for studying the effects of SB203580 on p38 activity in cell biological systems (Davis et al. 2005; Haq et al. 2002; Iwasa et al. 2003; Wang et al. 2002). To activate the $\mathrm{p} 38$-signalling pathway using anisomycin, HCA2.trt cells were plated onto $100 \mathrm{~mm}$ dishes in DMEM and cultured for 2 days at $37^{\circ} \mathrm{C}$, after which the cells were treated with $30 \mu \mathrm{M}$ anisomycin (Sigma, Poole, UK) for $45 \mathrm{~min}$.
Immunofluorescence microscopy

Actin staining for immunofluorescence microscopy was performed essentially as described (Huot et al. 1997). Briefly, the cells were plated into $35 \mathrm{~mm}$ plastic dishes in DMEM and allowed to settle for $48 \mathrm{~h}$. The cells were then washed in PBS, fixed in $3.7 \%$ paraformaldehyde for $20 \mathrm{~min}$ and permeabilised with $0.1 \%$ Triton-X100 for $20 \mathrm{~min}$. F-actin was detected using fluorescein isothiocyanate-conjugated (FITC)-conjugated phalloidin $(33 \mu \mathrm{g} / \mathrm{ml})$ (Sigma, Poole, UK), diluted 1:50 in PBS for $30 \mathrm{~min}$ in the dark, followed by washing in PBS.

Immunoblot analysis

Protein samples were prepared in lysis buffer containing the phosphatase inhibitors $\mathrm{NaF}$ and $\mathrm{Na}_{3} \mathrm{VO}_{4}$, separated on $12 \%$ sodium-dodecylsulphate/ polyacrylamide electrophoresis gels, electroblotted to immobilon-P polyvinylidene difluoride or nitrocellulose membranes (Millipore, Watford, UK) and antibodies applied as described previously (Davis et al. 2003). The antibodies used were: mouse monoclonal anti-HSP27 (G31), rabbit polyclonal anti-phospho(S82)-HSP27, anti-p38, anti-phospho(T180/Y182)-p38, rabbit monoclonal anti-JNK1/2 (56G8), anti-phospho(T183/Y185)-JNK1/2, rabbit monoclonal anti-c-Jun (60A8) (Cell Signalling, New England Biolabs, Hitchin, UK). An enhanced chemiluminescence kit (Amersham, Little Chalfont, UK) was used for visualisation using HRP-coupled goat secondary antibodies.

\section{Results}

Effects of SB203580 on the growth of normal adult dermal fibroblasts

Previous data has shown that the accelerated ageing seen in WS fibroblasts can be prevented by treatment of the cells with the p38 inhibitor SB203580 with the lifespan extension ranging up to $245 \%$ of replicative lifespan (Davis et al. 2005; see, Fig. 1e). However, the control cells used for the previous study were long-lived MRC5 foetal lung fibroblasts, whereas the WS cells were short-lived adult dermal cells. Thus, better control strains would seem to be age- and 
Fig. 1 Growth of AT and normal fibroblasts with or without treatment with SB203580. a-d Fibroblasts were grown in standard DMEM with no

supplementation (- $\bigcirc-$ ), with continual daily supplementation with SB203580 (-0-). Growth measured as PDs versus days. Only representative growth curves are given for AG13152(WT), AG09603(WT), AG03058(AT) and AG04405(AT) cells. e Bar chart comparing the effect of SB203580 on the experimental lifespan in AT, normal and WS cells. The lifespan extension for untreated cells is given as $0 \%$. For a definition of experimental lifespan see footnotes to Table 1
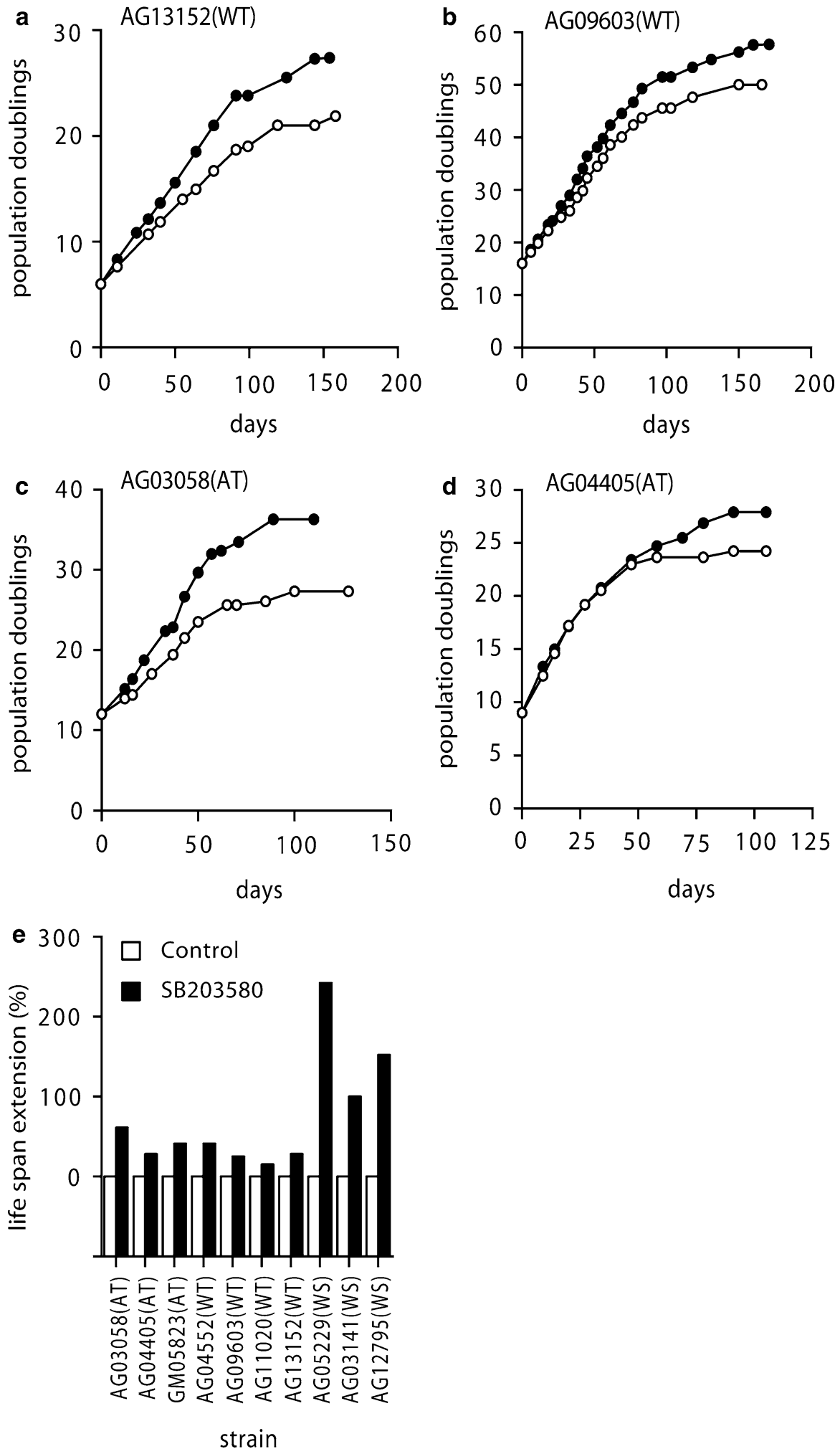
tissue-matched adult dermal cells with a range of replicative lifespans.

Thus, four strains of adult dermal fibroblasts were used in this study that were chosen to have a range of replicative lifespan from 21 to 50 PDs (Cristofalo et al. 1998). To assess the effects of treatment of primary adult fibroblasts with SB203580, cells were grown continuously in the presence or absence of the drug until they reached M1 senescence. The strain with the shortest lifespan, AG13152(WT), has an initial growth rate of $0.15 \mathrm{PDs} /$ day and a replicative lifespan of 24.0 PDs (Table 1; Fig. 1a). This growth rate increases to $0.18 \mathrm{PDs} /$ day in the presence of SB203580, and the replicative lifespan to 29.5 PDs, an increase in the experimental lifespan of $\sim 28 \%$ with the culture initiated at 6 PDs. The strain with an intermediate lifespan, AG11020(WT), has an initial growth rate of $0.34 \mathrm{PDs} /$ day and a replicative lifespan of 41.7 PDs (Table 1). In the presence of SB203580, these increase to $0.40 \mathrm{PD} /$ day and 46.5 PDs, which is an increase in replicative lifespan of $\sim 15 \%$ with the culture initiated at 9 PDs. The longest-lived strain, AG09603(WT), has an initial growth rate and lifespan in untreated cells of $0.35 \mathrm{PDs} /$ day and 47.8 PDs, that increases to $0.43 \mathrm{PDs} /$ day and 55.7 PDs when treated with SB203580, an increase of replicative lifespan of $\sim 25 \%$ with the culture initiated at 16 PDs (Table 1; Fig. 1b). Finally, for a second short-lived normal strain, AG04552(WT), an untreated growth rate and lifespan of $0.15 \mathrm{PDs} /$ day and 24.3 PDs increases to 0.19 PDs/day and 30.1 PDs with SB203580 treatment, an increase in experimental lifespan of $41 \%$ (Table 1). These increases in replicative lifespan for normal cells are very small when compared to that seen with WS cells (Fig. 1e; Davis et al. 2005). However, the observation that SB203580 can extend the replicative lifespan of normal adult dermal fibroblasts suggests that adult dermal cells would

Table 1 Growth parameters for Ataxia Telangiectasia and normal dermal fibroblasts grown in the presence or absence of SB203580

\begin{tabular}{|c|c|c|c|c|}
\hline Cell strain & SB203580 treatment & $\begin{array}{l}\text { Maximum growth } \\
\text { rate }(\mathrm{PD} / \text { day })^{\mathrm{a}}\end{array}$ & $\begin{array}{l}\text { Cellular lifespan } \\
(\mathrm{PD})^{\mathrm{a}}\end{array}$ & $\begin{array}{l}\text { Average increase } \\
\text { in lifespan }(\%)^{\mathrm{b}}\end{array}$ \\
\hline \multirow[t]{3}{*}{ AG03058(AT) } & - & $0.15 \pm 0.07$ & $24.02 \pm 2.84$ & \\
\hline & + & $0.31 \pm 0.07$ & $31.41 \pm 4.23(3)$ & 61.8 \\
\hline & $P$ value ${ }^{\mathrm{c}}$ & $P<0.024$ & $P<0.034$ & \\
\hline \multirow[t]{3}{*}{ AG04405(AT) } & - & $0.36 \pm 0.02$ & $23.52 \pm 0.64$ & \\
\hline & + & $0.40 \pm 0.03$ & $27.61 \pm 0.82(4)$ & 28.3 \\
\hline & $P$ value $^{\mathrm{c}}$ & $P<0.025$ & $P<0.00015$ & \\
\hline \multirow[t]{2}{*}{ GM05823(AT) } & - & 0.22 & 11.28 & \\
\hline & + & 0.29 & 15.98 & 41.7 \\
\hline \multirow[t]{2}{*}{ AG04552(WT) } & - & 0.15 & 24.28 & \\
\hline & + & 0.19 & 30.15 & 41.0 \\
\hline \multirow[t]{3}{*}{ AG09603(WT) } & - & $0.35 \pm 0.01$ & $47.76 \pm 3.17(2)$ & \\
\hline & + & $0.43 \pm 0.01$ & $55.73 \pm 2.72(2)$ & 25.1 \\
\hline & $P$ value $^{\mathrm{c}}$ & $P<0.008$ & $P>0.057$ & \\
\hline \multirow[t]{3}{*}{ AG11020(WT) } & - & $0.34 \pm 0.004(2)$ & $41.74 \pm 1.80(2)$ & \\
\hline & + & $0.40 \pm 0.042(2)$ & $46.55 \pm 2.70(2)$ & 14.7 \\
\hline & $P$ value ${ }^{\mathrm{c}}$ & $P<0.012$ & $P>0.085$ & \\
\hline \multirow[t]{3}{*}{ AG13152(WT) } & - & $0.15 \pm 0.0007$ & $24.0 \pm 3.01(2)$ & \\
\hline & + & $0.18 \pm 0.013(2)$ & $29.46 \pm 2.96(2)$ & 28.1 \\
\hline & $P$ value ${ }^{\mathrm{c}}$ & $P>0.03$ & $P>0.10$ & \\
\hline
\end{tabular}

\footnotetext{
${ }^{a}$ Mean \pm SD; number of cultures in brackets (for GM05823(AT) and AG04552(WT) only a single culture used). The maximum growth rate is based upon the linear part of the growth curve at early growth stages

b The experimental increase in lifespan achieved using SB203580 is calculated with reference to the starting PD: e.g., for AG13152(WT) the lifespan is $(27.4 \mathrm{PD}-6 \mathrm{PD}) /(24.3 \mathrm{PD}-6 \mathrm{PD})=1.41 \times$ control, or a $41 \%$ increase

c One-tailed $t$ test
} 
appear to be the correct baseline upon which to compare the effects of SB20580 on replicative lifespan.

Effects of SB203580 on the growth of AT adult dermal fibroblasts

Three strains of primary adult AT dermal fibroblasts were used. The AG03058(AT) cells have an average growth rate of $0.15 \mathrm{PDs} /$ day and a replicative lifespan of 24 PDs (Table 1; Fig. 1c). This lifespan is in agreement with previous studies (Tchirkov and Lansdorp 2003). Treatment of AG03058(AT) cells with SB203580 results in a significant increase in the growth rate to $0.31 \mathrm{PDs} /$ day. The average replicative lifespan of the AG03058(AT) cells also shows a significant increase to 31.4 PDs (Table 1). The experimental increase in lifespan is approximately $\sim 62 \%$, starting at a PD of 12. AG04405(AT) cells have an average growth rate of $0.36 \mathrm{PDs} /$ day and a replicative lifespan of 23.5 PDs (Table 1; Fig. 1d). This lifespan is again in agreement with previous work (Tchirkov and Lansdorp 2003). With SB203580 treatment, the growth rate increases to $0.40 \mathrm{PDs}$ /day and the lifespan to 27.6 PDs. These increases, although small, are both statistically significant. Finally, SB203580 treatment results in an increase in growth rate and replicative lifespan of GM05823(AT) cells (Table 1). The increase in experimental replicative lifespan is $41.7 \%$.

Examination of cellular morphology of AT, WS and normal fibroblasts

One of the striking features of young WS fibroblasts in culture is that they have an enlarged cellular morphology with an extensive network of F-actin stress fibres (Davis et al. 2005), and when young AG05229(WS) cells are stained with phalloidin-FITC the enlarged morphology and F-actin fibres can be clearly seen (Fig. 2a). Continuous treatment of the WS cells with SB203580 (Fig. 2b) alleviates this cellular morphology and the cells now resemble young normal cells (see, Fig. 2m, right panel). A similar phenotype is seen with young AG03141(WS) cells, where most of the control cells have extensive F-actin stress fibres that are alleviated with continuous SB203580 treatment (Fig. 2c, d).

It has been reported previously that primary fibroblasts from AT individuals also have an enlarged morphology compared to normal primary fibroblasts, with an altered micro-filament array (McKinnon and Burgoyne 1985), and thus the AT cells resemble WS cells in this regard. The cells used in the previous study included GM05823(AT) cells. In this work we have examined the morphology of replicatively young GM05823(AT) cells and stained them with phalloidin-FITC to visualise the F-actin stress fibres. In a young population of GM05823(AT) cells (Fig. 2e), a few enlarged cells can be seen. However, the majority of the cells have a small morphology resembling young normal cells (Fig. $2 \mathrm{~m}$, right panel). The actual ratio of large irregular cells was not calculated, however, it is estimated to be $<5 \%$. When the cells are treated with phalloidin-FITC to stain the F-actin filaments (Fig. 2f), an extensive network of stress fibres is observed only in the large irregular cells. Growth of GM05823(AT) cells in medium supplemented with SB203580 has little effect on the size distribution of the cells, however, the large irregular cells do not appear as granular in appearance (Fig. 2g). When stained with phalloidin-FITC (Fig. 2h) the enlarged cells still have numerous F-actin stress fibres. A similar situation is found for young AG03058(AT) cells (Fig. 2i, j) with the cell populations having a few enlarged cells with numerous stress fibres, but most of the cells having a small young-looking morphology. As with GM05823(AT) cells, the morphology distribution is not affected by SB203580 treatment (Fig. 2k, 1). Finally, with young AG04405(AT) cells, very few cells have an enlarged morphology and SB203580 treatment has no effect on this morphology (data not shown).

We also examined normal adult dermal fibroblast strains using both phase contrast and phalloidin-FITC staining. With young AG11020(WT) cells (Fig. 2m), essentially the same pattern is seen as for the AT cells of a similar small number of enlarged cells with extensive stress fibres, with the majority of the cells having a normal morphology. Again SB203580 treatment has little effect on these cells (Fig. 2n). A similar pattern is seen in all the normal adult fibroblast strains used in this study (data not shown).

When the AT, WS and normal adult dermal fibroblasts reach M1 senescence, the majority of the cells have the enlarged morphology with extensive F-actin stress fibres typical of senescent cells, for both untreated cells and cells grown continuously in SB203580 (data not shown and, Davis et al. 2005). 

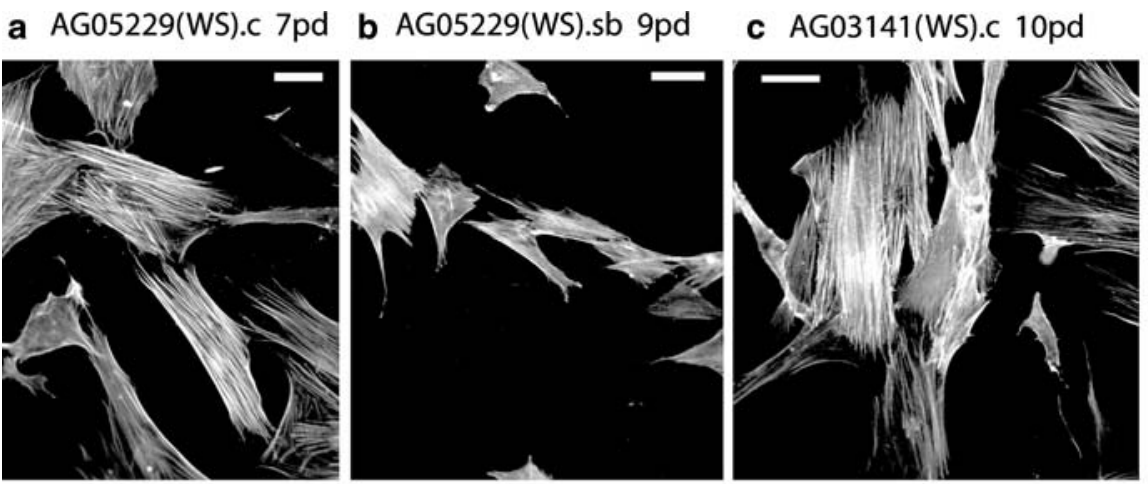

d AG03141(WS).sb 12pd

e GM05823(AT).c 3PD

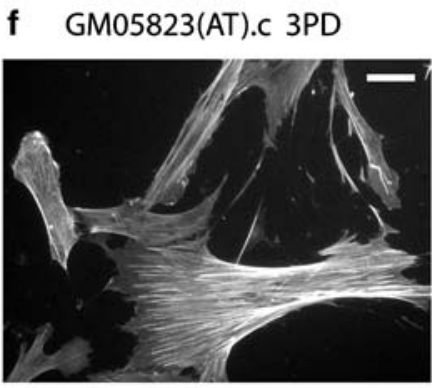

g GM05823(AT).sb 6PD
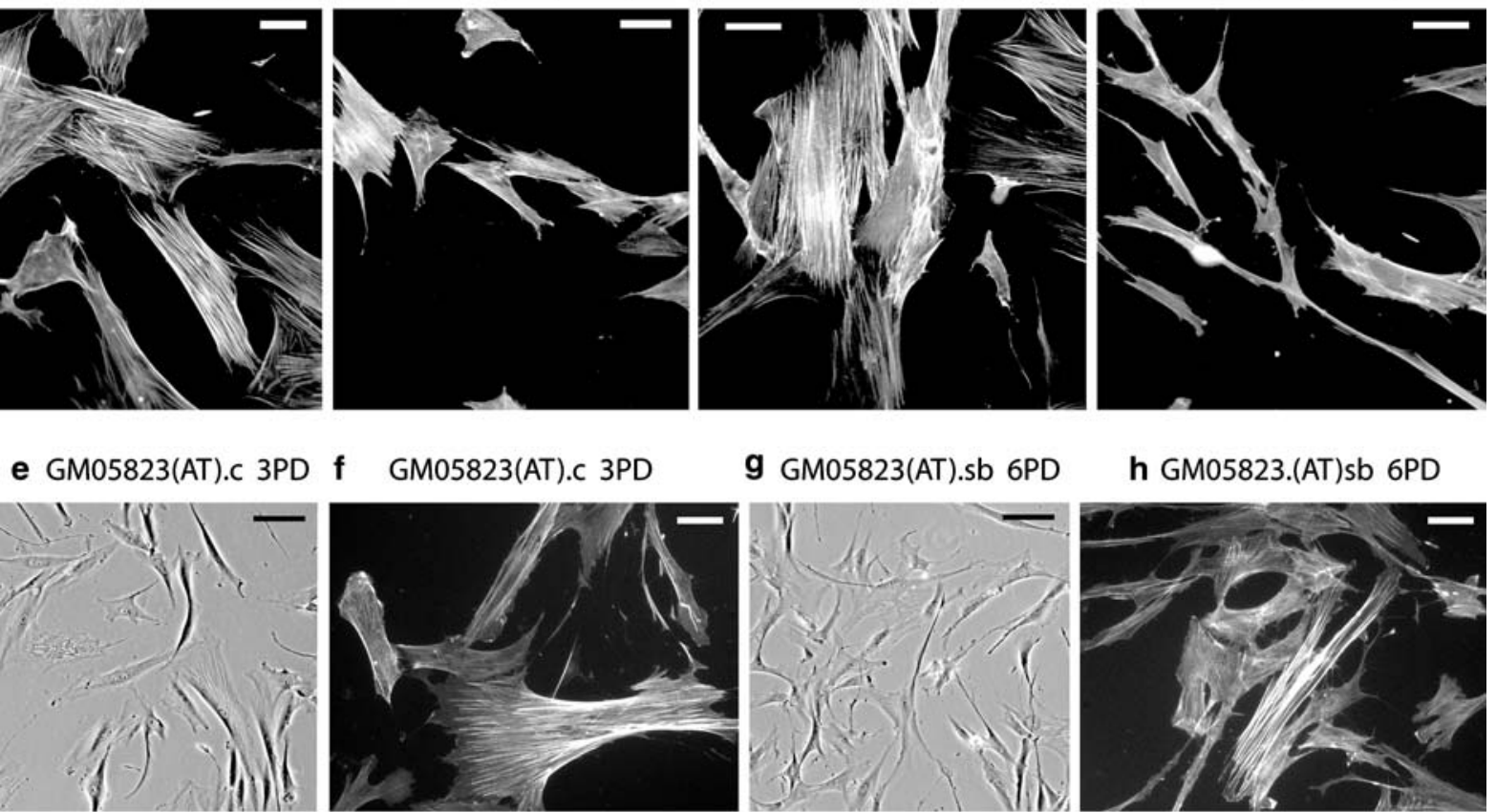

h GM05823.(AT)sb 6PD

\section{i AG03058(AT).c 14PD}

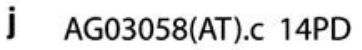

\section{k AG03058(AT).sb 15PD}
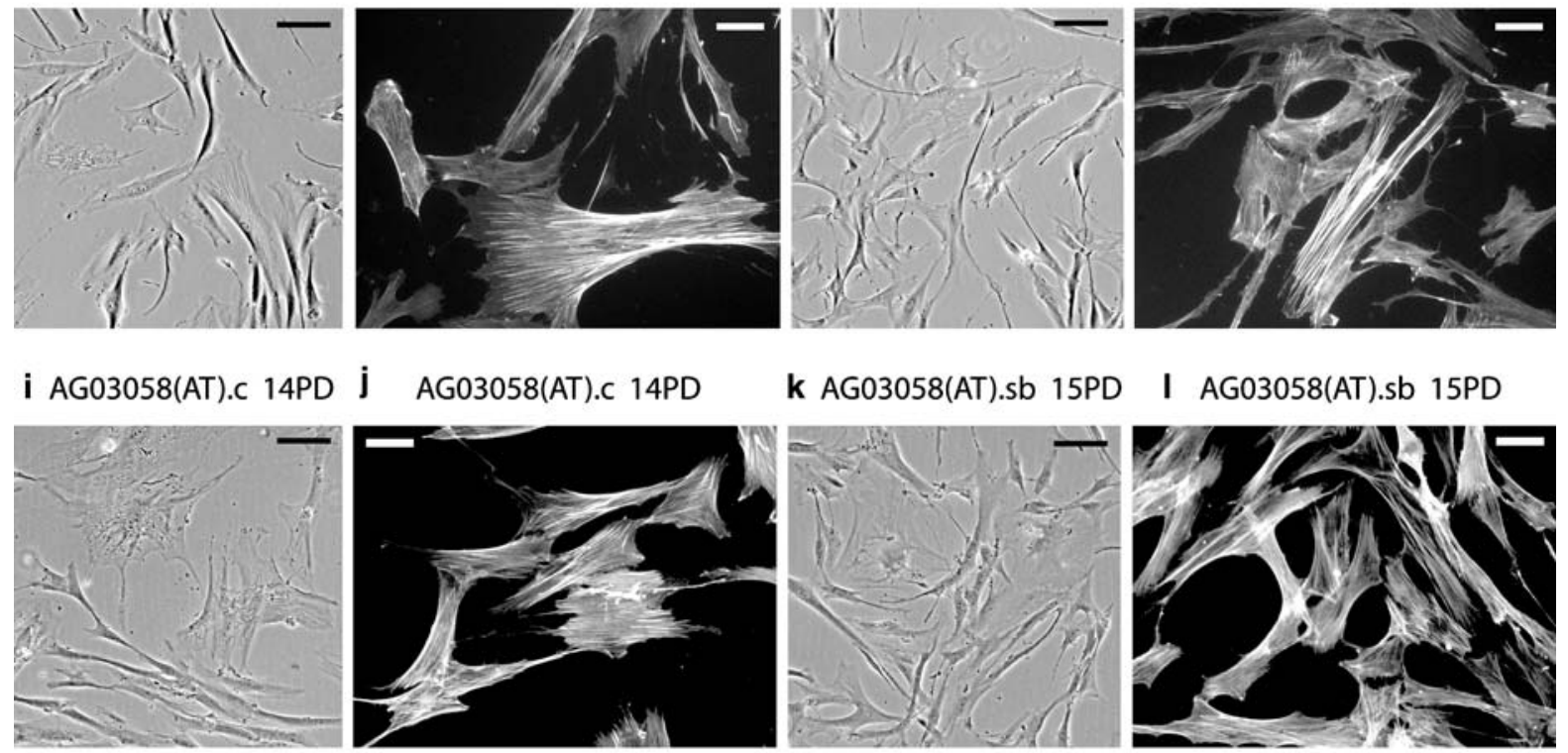

\section{m AG11020(WT).c 11PD}
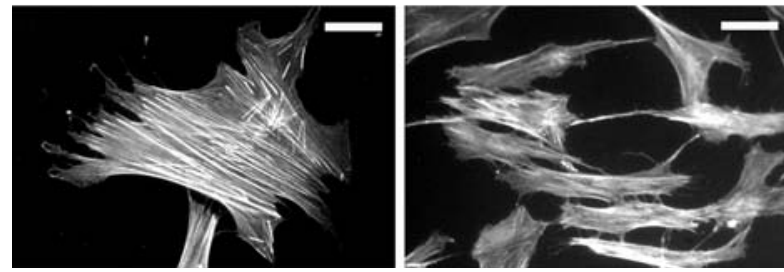

n AG11020(WT).sb 12PD
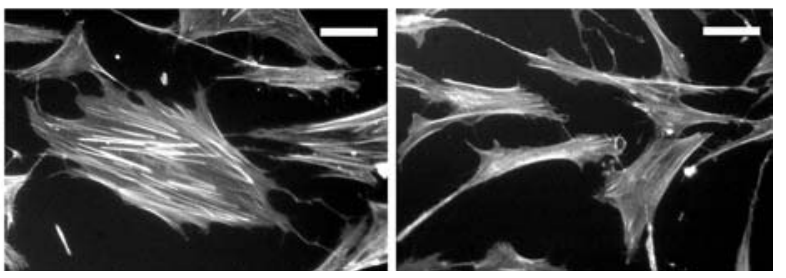

Fig. 2 Observation of cellular morphology and F-actin stress fibres in AT, WS and normal fibroblasts. For morphology, live cells were examined by phase contrast microscopy (e, $\mathbf{g}, \mathbf{i}, \mathbf{k})$. For examination of stress fibres cells were fixed and stained with phalloidin-FITC (a, b, c, d, f, h, j, l, m, n). For each panel, the cell type and PD values are given: note that the control and SB203580 treated cells were grown for the same lengths of

As normal cells at the end of their replicative lifespan have F-actin stress fibres that are insensitive to SB203580 treatment, this suggests that the large

time so the PD value for the treated cells will be slightly higher due to slightly more rapid growth and the control cells maintained their morphology until they reached senescence. A suffix.c are control cells and a suffix.sb are cells treated with SB203580. Panels $\mathbf{m}$ and $\mathbf{n}$ are composites of two different representative views of the phalloidin stained cells. Black bars are $100 \mu \mathrm{m}$; white bars are $50 \mu \mathrm{m}$

irregular cells seen in the young populations in AT and WT cells have undergone replicative senescence through the normal "stochastic" processes, perhaps 
dependent upon telomere erosion, and that this senescence is independent of $\mathrm{p} 38$.

Characterisation of stress kinase effector pathways

To assess the activation status of p38 in normal and AT fibroblasts, proteins were extracted from young cells grown in the presence or absence of SB203580, and Western blots were probed with antibodies for p38 and its activating phosphorylation (Fig. 3a). Little activation of p38 is seen in either normal AG09603(WT) cells or in AG03058(AT) AT cells, as indicated by the low levels of phosphorylated p38. There is also very little phosphorylation of the small heat shock protein HSP27 at the Ser82 site in these cells. As a control, Fig. 3a demonstrates that HCA2.trt cells that have been stimulated with anisomycin, which is known to activate the p38 pathway, show high levels of both phosphorylated p38 and HSP27 (Fig. 3a). As HSP27 is a major downstream target of the p38 pathway via the kinase MK2 (Huot et al. 1997), these data strongly suggest that the p38 kinase signalling pathway is not significantly activated in AT cells. In contrast, p38 is activated in young AG03141(WS) cells (Fig. 3b) and, interestingly, SB203580 treatment appears to prevent this activation for reasons that are unclear (Davis et al. 2005). Activation of the p38 pathway is also seen in young AG05229(WS) cells (Davis et al. 2007). The activated $p 38$ results in increased levels of phosphorylated HSP27 in the WS cells, which is prevented in cells treated with SB203580 (Davis et al. 2005, 2007).

The c-Jun N-terminal kinases (JNKs) are also activated in response to stress (Davis 2000), so we determined the level of activated JNKs in the AT and normal cells (Fig. 3a). In untreated AG03058(AT) cells, activated $\mathrm{JNK} 1 / 2$ is barely detectable. In AG03058(AT) cells treated with SB203580, low levels of the phosphorylated p46 versions of JNK1/2 are seen (Fig. 3a). These are the JNK $1 \alpha 1$ and JNK $2 \alpha 1$ isoforms of JNK (Liu et al. 2004). The increased amounts of activated JNK1/2 may reflect the increased levels of JNK $1 / 2$ in the treated cells, or may indicate that JNK1/2 are activated to a low level in SB203580 treated cells. Interestingly, there is an elevated level of $\mathrm{p} 46 \mathrm{JNK}$ activation in the normal

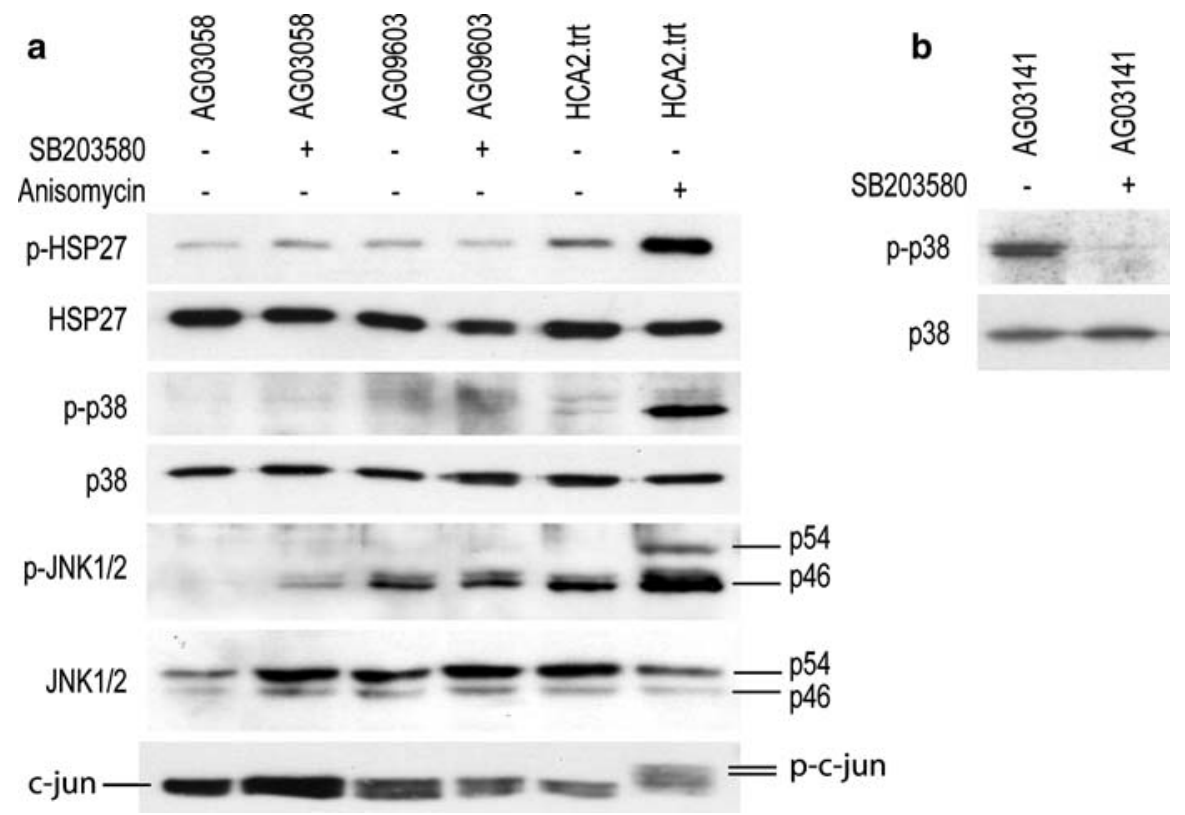

Fig. 3 Immunoblot analysis of proteins from cells grown in the presence or absence of SB203580. a Protein lysates were prepared from primary AG03058(AT) and AG09603(WT) cells and from hTERT-immortalised HCA2 cells. b Protein lysates were prepared from primary AG03141(WS) cells. Expression levels were compared for phosphorylated p38 (p-p38), p38, phosphorylated JNK1/2 (p-JNK1/2), JNK1/2, phosphorylated HSP27 (p-HSP27), HSP27 and c-Jun. For JNK1/2 the p46 and p54 kDa versions are indicated, and phosphorylated c-Jun versions are shown (p-c-Jun). For each blot an equal amount $(15 \mu \mathrm{g})$ of protein was loaded per sample 
cells as compared to the AT cells, although this is still at a low level when compared to that seen in anisomycin treated HCA2.trt cells. This low level of JNK activation is confirmed by the low levels of detectable phosphorylated forms of c-Jun in the AT and normal cell strains compared to anisomycin treated HCA2.trt cells (Fig. 3a).

\section{Discussion}

Normal human fibroblasts have a limited replicative lifespan in culture before they enter an irreversible non-dividing state termed M1 or senescence (Hayflick and Moorhead 1961; Shay and Wright 2000). Cellular senescence is not death, but resembles terminal differentiation in that the cells have a morphology and pattern of gene expression that differs markedly from their dividing counterparts (Itahana et al. 2004; Kipling et al. 2004). This replicative senescence has been postulated to contribute to human ageing and senescent cells have been found in many human tissues during ageing (Davis and Kipling 2006; and references therein). Cellular senescence may contribute to age-related degenerations due to reduced proliferative capacity in tissues that require continuous division throughout life and/or, due to the deleterious features of senescent cells such as the secretion of degradative enzymes and inflammatory cytokines. However, the actual role, if any, of cellular senescence in human ageing is disputed (Rubin 2002). The study of human ageing is aided by model systems that reflect upon aspects of the ageing process, the so-called progeroid syndromes (Kipling et al. 2004; Cox and Faragher 2007; Kudlow et al. 2007). In this paper we describe results from growth experiments using fibroblasts from two of these syndromes that manifest accelerated cellular senescence, AT and WS.

Although replicative senescence in human fibroblasts is thought to result from the progressive loss of telomeric DNA with ongoing cell division, the premature senescence of WS fibroblasts is not due to accelerated telomere shortening (Baird et al. 2004), but appears to result from the activation of the stressinduced p38 MAP kinase, and young WS fibroblasts have an altered cellular morphology that resembles cells having undergone SIPS (Davis et al. 2005). Treatment of WS cells with the p38 kinase inhibitor SB203580 effectively prevents the accelerated ageing seen in WS cells, suggesting that this premature ageing is indeed due to SIPS. In addition, these data raise the possibility that p38 inhibitors may one day provide therapeutic options for WS individuals by preventing this accelerated cellular ageing (Davis and Kipling 2006). However, there are two possible criticisms of the original study: firstly, the use of the foetal lung cell strain MRC5 as a control for SB203580-induced lifespan extension; secondly, the control cells had a long replicative lifespan (Davis et al. 2005). As the WS cells were short-lived adult dermal cells, it is possible that the effects seen with SB203580 were due to a combination of an adult dermal cell-specific effect and a short lifespan. As normal human adult dermal fibroblasts have a replicative lifespan ranging from approximately 25 to 70 PDs (Cristofalo et al. 1998), it is possible that SB203580 treatment would have a similar effect on short-lived normal cells as is seen for WS cells.

Therefore, in this study, we have used four normal adult dermal fibroblast strains that have replicative lifespans ranging from 24 to 48 PDs (Cristofalo et al. 1998). The lifespans of the short-lived normal strains are at the upper range of the WS strains (Davis et al. 2005). For each cell strain, treatment with SB203580 extended their replicative lifespan, however, the increases in experimental lifespan only ranged from 15 to $41 \%$. This compares to an increase in experimental lifespan for three WS strains of 100, 175 and 245\% (see, Fig. 1e) (Davis et al. 2005). SB203580 treatment also increased the growth rate of the normal cells by up to $30 \%$ (Table 1). By comparison, the increased growth rate seen in SB203580-treated WS cells was between 128 and 160\% (Davis et al. 2005). In addition, the majority of the young normal dermal cells have a small cellular morphology lacking F-actin stress fibres, and p38 was activated in these cells. Finally, SB203580 treatment extends the experimental lifespan of HCA2 neonatal dermal fibroblasts by $41 \%$, but has no effect on the cellular morphology, and p38 is not activated in young HCA2 cells (Davis et al. 2007). These combined data provide strong supporting evidence that the effects of SB203580 on WS cellular lifespan are mainly due to the loss of WRN resulting in SIPS via $\mathrm{p} 38$ activation.

In addition to using normal adult fibroblasts, we have extended this study to AT, a progeroid syndrome that is also associated with fibroblasts that are reported to have an altered cellular morphology characteristic of cells undergoing SIPS, and show 
accelerated replicative senescence. Treatment with the p38 specific inhibitor SB203580 does increase the replicative lifespan of AT cells, albeit only by between 28 and $60 \%$ of experimental lifespan. The increase in lifespan for two of the strains is within the range seen for normal cells, however, the increased lifespan seen in AG03058(AT) cells is intermediate between that of normal and WS cells (see, Fig. 1e). Finally, in contrast to previous reports (McKinnon and Burgoyne 1985), we find that the cellular morphology of young fibroblasts from three AT individuals is essentially identical to that seen in three normal adult dermal fibroblast strains, where the cultures consist of a few enlarged cells with the majority of the cells having a normal morphology. This morphology is quite distinct to the morphology seen in young WS fibroblasts. Daily treatment with SB203580 had little effect on this morphology. This lack of enlarged morphology and F-actin stress fibres correlates well with the lack of p38 activation and subsequent phosphorylation of HSP27 seen in both AT and normal cells. In summary, the only phenotypic manifestation seen in the AT cells in this study compared to normal adult dermal fibroblasts, was that they all had an in vitro lifespan of $<25$ PDs, which was in the range of the shortest lifespan seen for normal cells. The data reported in this work strongly suggest that the short replicative lifespan of AT cells is not due to SIPS via p38 activation.

Both AT and WS are associated with accelerated cellular senescence, however, the senescence mechanism differs for each syndrome. Recent evidence suggests that WRN cooperates with ATM to implement an intra-S phase checkpoint in cells with collapsed replication forks, with WRN being required for ATM activation (Cheng et al. 2008). The primary sensor of stalled replication forks is ATR, which recruits the MRN complex and RAD51 and RAD52, with fork stalls being repaired via a homologous recombination dependent process (Pichierri and Franchitto 2004). The WRN protein appears to be required to resolve the recombinational intermediate, an idea supported by the observation that the growth defect of WS cells can be corrected by ectopic expression of the bacterial resolvase RusA (Rodriguez-Lopez et al. 2007). This resolution creates a double-strand break (DSB) that is then repaired in an ATMdependent fashion (Shiloh 2003). DSBs are also created as a result genomic insults such as oxidative stress or $\gamma$ irradiation, and by cellular processes such as $\mathrm{V}(\mathrm{D}) \mathbf{J}$ recombination or telomere replication (Shiloh 1997; Verdun and Karlseder 2006). Such DSBs are also repaired in an ATM-dependent fashion, but this repair does not appear to require WRN to activate ATM (Bolderson et al. 2004; Cheng et al. 2008). In other words, WRN and ATM are epistatic in the repair of DSBs induced by replication fork stalls, but DSBs resulting from other processes are repaired independently of WRN (Fig. 4). This model predicts that cells lacking WRN would undergo replication fork blockage and cell cycle arrest in an ATM-independent fashion, whereas in cells lacking ATM there would be an increase in DSBs leading to senescence, perhaps dependent upon ATR (Herbig et al. 2004).

Indeed, WS cells are hyper-sensitive to a certain type of DNA damaging agent that blocks replication fork progression, and there is a high level of replication fork stalling (Rodriguez-Lopez et al. 2002). As WRN is required for the recombinational resolution of fork stall repair, in WS cells there is a failure to restart the replication fork. This failure results in a condition termed 'replication stress' that then activates p38 resulting in cellular senescence (Davis et al. 2007; Pichierri and Franchitto 2004; Rodriguez-Lopez et al. 2002). As this replication stress is 'stochastic' this would lead to premature senescence in a subset of WS cells at each division,

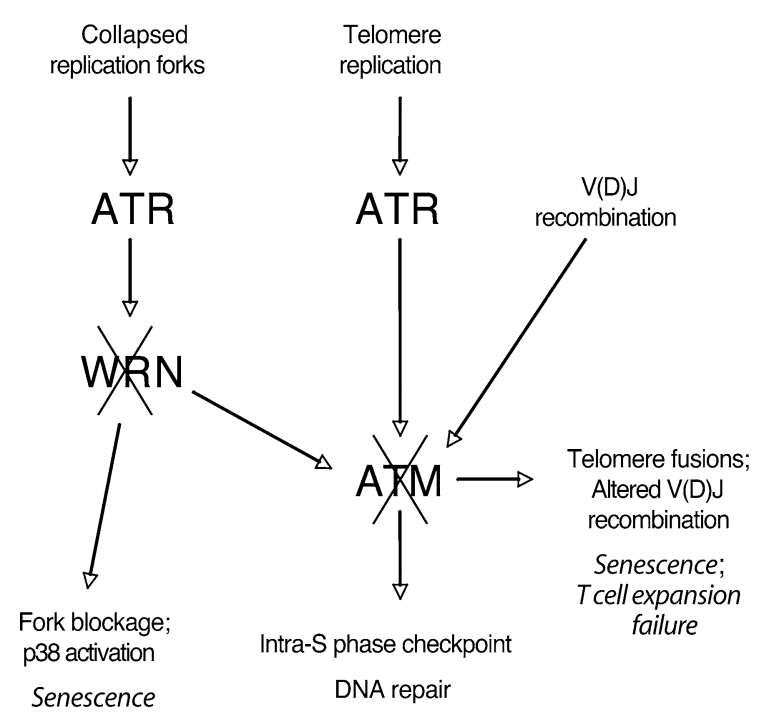

Fig. 4 Model for the role of WRN and ATM in telomere replication and $\mathrm{V}(\mathrm{D}) \mathrm{J}$ rejoining, and in response to collapsed replication forks 
exactly what is observed (Baird et al. 2004; Faragher et al. 1993). This idea is supported by the observation that resolution of the recombinational blockage by ectopic expression of the bacterial resolvase RusA corrects the growth defect of WS cells (RodriguezLopez et al. 2007). Once the blockage has been resolved the DSB can be repaired by ATM action, and the replication fork can proceed.

In contrast to WS, a significant feature of AT cells is a high incidence of telomere fusions (Pandita et al. 1995). The replication of telomeres by DNA polymerases leads to the exposure of single stranded DNA that is detected by Mre11 and RPA, which then activate ATR, so as to initiate completion of telomere replication. This leads to the production of a DSB with a short $3^{\prime}$ overhang that triggers an ATM-dependent production of the t- and D-loop structures that protect the telomere end (see, Verdun and Karlseder 2006, for details). This model predicts that loss of ATM would stall telomere replication resulting in the production of DSBs. It may be the generation of these DSBs that leads to the telomere fusions seen in AT cells. These telomere fusions then lead to increased rates of apoptosis and/or cellular senescence.

This model then provides a possible explanation for the clinical manifestation in AT and WS. Features in common include, premature grey hair, alopecia, skin atrophy and sclerosis, phenotypes which may result from the build-up of senescent cells in tissues, or be due to reduced renewal ability of these tissues due to replicative exhaustion. If so, then the actual mechanism by which these cells undergo accelerated ageing may not be directly relevant, the important point being the actual presence and build-up of the senescent cells (Bird et al. 2003; Hofer et al. 2005; Kipling et al. 2004). In WS, this accelerated senescence results from stress-induced p38 activation, whereas in AT it is due to the high incidence of telomere fusions.

However, there are clinical features that distinguish the two syndromes; in AT it is immunodeficiency and ataxia, whereas in WS it is inflammatory diseases such as atherosclerosis, type II diabetes, and osteoporosis. Here the actual mechanism underlying the accelerated cellular senescence may have clinical relevance. Although the actual aetiology of the ataxia is not fully understood, the immunodeficiency in AT appears to be due to the inability of $\mathrm{T}$ cell expansion, resulting from lack of ATM leading to inappropriate V(D)J recombination in $\mathrm{T}$ cell receptor and immunoglobulin genes
(Kojis et al. 1991), acting in concert with the telomere fusion induced senescence. The inflammatory phenotypes seen in WS, however, may result from the activation of p38. Inflammatory diseases are associated with up-regulation of inflammatory cytokines such as IL- 1 and TNF $\alpha$, both of which are downstream in the p38-signalling pathway, and WS individuals have elevated TNF $\alpha$ levels in vivo (Davis and Kipling 2006; Yokote et al. 2004). Thus, the presence of activated p38 in WS cells may predispose individuals to inflammatory disease, and the lack of p38 activation in young AT cells may reflect the in vivo manifestation, as AT is not reported to be associated with inflammatory diseases (Crawford 1998; Lavin and Shiloh 1997; Rotman and Shiloh 1998).

In summary, the results described in this study provide indirect support for the hypothesis that the prevention of accelerated ageing in WS fibroblasts by SB203580 is due inhibition of p38, and suggest a role for SIPS p38 activity in the clinical features of WS. If premature ageing of cells and p38 activation do underlie the accelerated ageing of WS individuals, then the recent development of a fully reflective mouse model of WS (Chang 2005) now makes future studies possible as to whether p38 inhibitors will be effective as therapeutic agents in a premature ageing disease. Some of these p38 inhibitors have undergone phase II and III clinical trials for inflammatory disease (Saklatvala 2004). In addition, we have synthesised and tested some of these inhibitors for their efficacy to inhibit p38 in WS cells, and studies as to their effectiveness in ameliorating WS cellular phenotypes are ongoing (Bagley et al. 2006, 2007, 2008).

Acknowledgements This work was supported by the Biotechnology and Biological Sciences Research Council (BB/D5241401; 75/ERA16281), and the Engineering and Physical Sciences Research Council/Biotechnology and Biological Sciences Research Council SPARC Initiative.

Open Access This article is distributed under the terms of the Creative Commons Attribution Noncommercial License which permits any noncommercial use, distribution, and reproduction in any medium, provided the original author(s) and source are credited.

\section{References}

Bagley MC, Davis T, Dix MC, Widdowson CS, Kipling D (2006) Microwave-assisted synthesis of $N$-pyrazole ureas and the p38alpha inhibitor BIRB 796 for study into 
accelerated cell ageing. Org Biomol Chem 4:4158-4164. doi:10.1039/b611493h

Bagley MC, Davis T, Dix MC, Rokicki MJ, Kipling D (2007) Rapid synthesis of VX-745: p38 MAP kinase inhibition in Werner syndrome cells. Bioorg Med Chem Lett 17: 5107-5110. doi:10.1016/j.bmcl.2007.07.016

Bagley MC, Davis T, Dix MC, Murziani PG, Rokicki MJ, Kipling D (2008) Microwave-assisted synthesis of 5-aminopyrazol-4-yl ketones and the p38(MAPK) inhibitor RO3201195 for study in Werner syndrome cells. Bioorg Med Chem Lett 18:3745-3748. doi:10.1016/j.bmcl.2008. 05.037

Baird DM, Davis T, Rowson J, Jones CJ, Kipling D (2004) Normal telomere erosion rates at the single cell level in Werner syndrome fibroblast cells. Hum Mol Genet 13:1515-1524. doi: $10.1093 / \mathrm{hmg} / \mathrm{ddh} 159$

Ball LG, Xiao W (2005) Molecular basis of ataxia telangiectasia and related diseases. Acta Pharmacol Sin 26:897907. doi:10.1111/j.1745-7254.2005.00165.x

Barzilai A, Rotman G, Shiloh Y (2002) ATM deficiency and oxidative stress: a new dimension of defective response to DNA damage. DNA Repair (Amst) 1:3-25. doi:10.1016/ S1568-7864(01)00007-6

Bird J, Ostler EL, Faragher RG (2003) Can we say that senescent cells cause ageing? Exp Gerontol 38:13191326. doi:10.1016/j.exger.2003.09.011

Bolderson E, Scorah J, Helleday T, Smythe C, Meuth M (2004) ATM is required for the cellular response to thymidine induced replication fork stress. Hum Mol Genet 13:29372945. doi: $10.1093 / \mathrm{hmg} / \mathrm{ddh} 316$

Chang S (2005) A mouse model of Werner syndrome: what can it tell us about aging and cancer? Int J Biochem Cell Biol 37:991-999. doi:10.1016/j.biocel.2004.11.007

Cheng WH, Muftic D, Muftuoglu M, Dawut L, Morris C, Helleday T, Shiloh Y, Bohr VA (2008) WRN is required for ATM Activation and the S-Phase checkpoint in response to interstrand crosslink-induced DNA double strand breaks. Mol Biol Cell 19:3923-3933. doi:10.1091/ mbc.E07-07-0698

Cox LS, Faragher RGA (2007) From old organisms to new molecules: integrative biology and therapeutic targets in accelerated human ageing. Cell Mol Life Sci 64: 2620-2641. doi:10.1007/s00018-007-7123-x (Review)

Crawford TO (1998) Ataxia telangiectasia. Semin Pediatr Neurol 5:287-294. doi:10.1016/S1071-9091(98)80007-7

Cristofalo VJ, Allen RG, Pignolo RJ, Martin BG, Beck JC (1998) Relationship between donor age and the replicative lifespan of human cells in culture: a reevaluation. Proc Natl Acad Sci USA 95:10614-10619. doi:10.1073/pnas.95.18.10614

Davis RJ (2000) Signal transduction by the JNK group of MAP kinases. Cell 103:239-252. doi:10.1016/S0092-8674(00) 00116-1

Davis T, Kipling D (2006) Werner syndrome as an example of inflamm-aging: possible therapeutic opportunities for a progeroid syndrome? Rejuvenation Res 9:402-407. doi: 10.1089/rej.2006.9.402

Davis T, Kipling D (2007) Werner syndrome, telomeres and stress signalling: implications for future therapies? In: Rudolph KL (ed) Telomeres and telomerase in ageing, disease, and cancer. Springer, Berlin, pp 285-308
Davis T, Singhrao SK, Wyllie FS, Haughton MF, Smith PJ, Wiltshire M, Wynford-Thomas D, Jones CJ, Faragher RG, Kipling D (2003) Telomere-based proliferative lifespan barriers in Werner-syndrome fibroblasts involve both p53dependent and p53-independent mechanisms. J Cell Sci 116:1349-1357. doi:10.1242/jcs.00331

Davis T, Baird DM, Haughton MF, Jones CJ, Kipling D (2005) Prevention of accelerated cell aging in Werner syndrome using a p38 mitogen-activated protein kinase inhibitor. J Gerontol A Biol Sci Med Sci 60:1386-1393

Davis T, Haughton MF, Jones CJ, Kipling D (2006) Prevention of accelerated ageing in the Werner syndrome. Ann N Y Acad Sci 1067:243-247. doi:10.1196/annals.1354.031

Davis T, Wyllie FS, Rokicki MJ, Bagley MC, Kipling D (2007) The role of cellular senescence in Werner syndrome: toward therapeutic intervention in human premature aging. Ann N Y Acad Sci 1100:455-469. doi:10.1196/ annals.1395.051

Deng Q, Liao R, Wu BL, Sun P (2004) High intensity ras signaling induces premature senescence by activating $\mathrm{p} 38$ pathway in primary human fibroblasts. J Biol Chem 279:1050-1059. doi:10.1074/jbc.M308644200

Elmore E, Swift M (1976) Growth of cultured cells from patients with ataxia-telangiectasia. J Cell Physiol 89: 429-431. doi:10.1002/jcp.1040890308

Faragher RG, Kill IR, Hunter JA, Pope FM, Tannock C, Shall S (1993) The gene responsible for Werner syndrome may be a cell division "counting" gene. Proc Natl Acad Sci USA 90:12030-12034. doi:10.1073/pnas.90.24.12030

Guay J, Lambert H, Gingras-Breton G, Lavoie JN, Huot J, Landry J (1997) Regulation of actin filament dynamics by p38 map kinase-mediated phosphorylation of heat shock protein 27. J Cell Sci 110(Pt 3):357-368

Haq R, Brenton JD, Takahashi M, Finan D, Finkielsztein A, Damaraju S, Rottapel R, Zanke B (2002) Constitutive p38HOG mitogen-activated protein kinase activation induces permanent cell cycle arrest and senescence. Cancer Res 62:5076-5082

Harley CB, Futcher AB, Greider CW (1990) Telomeres shorten during ageing of human fibroblasts. Nature 345:458-460. doi: $10.1038 / 345458 \mathrm{a} 0$

Hayflick L, Moorhead PS (1961) The serial cultivation of human diploid cell strains. Exp Cell Res 25:585-621. doi: 10.1016/0014-4827(61)90192-6

Herbig U, Jobling WA, Chen BP, Chen DJ, Sedivy JM (2004) Telomere shortening triggers senescence of human cells through a pathway involving ATM, p53, and p21(CIP1), but not p16(INK4a). Mol Cell 14:501-513. doi: 10.1016/S1097-2765(04)00256-4

Hoar DI (1975) Letter: phenotypic manifestations of ataxiatelangiectasia. Lancet 2:1048. doi:10.1016/S0140-6736 (75)90347-5

Hofer AC, Tran RT, Aziz OZ, Wright W, Novelli G, Shay J, Lewis M (2005) Shared phenotypes among segmental progeroid syndromes suggest underlying pathways of aging. J Gerontol A Biol Sci Med Sci 60:10-20

Huot J, Houle F, Marceau F, Landry J (1997) Oxidative stressinduced actin reorganization mediated by the $\mathrm{p} 38$ mitogenactivated protein kinase/heat shock protein 27 pathway in vascular endothelial cells. Circ Res 80:383-392 
Itahana K, Campisi J, Dimri GP (2004) Mechanisms of cellular senescence in human and mouse cells. Biogerontology 5:1-10. doi:10.1023/B:BGEN.0000017682.96395.10

Iwasa H, Han J, Ishikawa F (2003) Mitogen-activated protein kinase p38 defines the common senescence-signalling pathway. Genes Cells 8:131-144. doi:10.1046/j.13652443.2003.00620.x

Kastan MB, Lim DS (2000) The many substrates and functions of ATM. Nat Rev Mol Cell Biol 1:179-186. doi: $10.1038 / 35043058$

Kim GY, Mercer SE, Ewton DZ, Yan Z, Jin K, Friedman E (2002) The stress-activated protein kinases p38 alpha and JNK1 stabilize p21(Cip1) by phosphorylation. J Biol Chem 277:29792-29802. doi:10.1074/jbc.M201299200

Kipling D, Davis T, Ostler EL, Faragher RG (2004) What can progeroid syndromes tell us about human aging? Science 305:1426-1431. doi:10.1126/science. 1102587

Kojis TL, Gatti RA, Sparkes RS (1991) The cytogenetics of ataxia telangiectasia. Cancer Genet Cytogenet 56: 143-156. doi:10.1016/0165-4608(91)90164-P

Kudlow BA, Kennedy BK, Monnat RJ Jr (2007) Werner and Hutchinson-Gilford progeria syndromes: mechanistic basis of human progeroid diseases. Nat Rev Mol Cell Biol 8:394-404. doi:10.1038/nrm2161

Lavin MF, Shiloh Y (1997) The genetic defect in ataxia-telangiectasia. Annu Rev Immunol 15:177-202. doi: 10.1146/annurev.immunol.15.1.177

Liu J, Minemoto Y, Lin A (2004) c-Jun N-terminal protein kinase 1 (JNK1), but not JNK2, is essential for tumor necrosis factor alpha-induced c-Jun kinase activation and apoptosis. Mol Cell Biol 24:10844-10856. doi:10.1128/ MCB.24.24.10844-10856.2004

Martin GM, Oshima J, Gray MD, Poot M (1999) What geriatricians should know about the Werner syndrome. J Am Geriatr Soc 47:1136-1144

McKinnon PJ, Burgoyne LA (1985) Altered cellular morphology and microfilament array in ataxia-telangiectasia fibroblasts. Eur J Cell Biol 39:161-166

Metcalfe JA, Parkhill J, Campbell L, Stacey M, Biggs P, Byrd PJ, Taylor AM (1996) Accelerated telomere shortening in ataxia telangiectasia. Nat Genet 13:350-353. doi:10.1038/ ng0796-350

Naka K, Tachibana A, Ikeda K, Motoyama N (2004) Stressinduced premature senescence in hTERT-expressing ataxia telangiectasia fibroblasts. J Biol Chem 279: 2030-2037. doi:10.1074/jbc.M309457200

Pandita TK (2002) ATM function and telomere stability. Oncogene 21:611-618. doi:10.1038/sj.onc.1205060

Pandita TK, Pathak S, Geard CR (1995) Chromosome end associations, telomeres and telomerase activity in ataxia telangiectasia cells. Cytogenet Cell Genet 71:86-93. doi: 10.1159/000134069

Pichierri P, Franchitto A (2004) Werner syndrome protein, the MRE11 complex and ATR: menage-a-trois in guarding genome stability during DNA replication? Bioessays 26:306-313. doi:10.1002/bies.10411

Rodriguez-Lopez AM, Jackson DA, Iborra F, Cox LS (2002) Asymmetry of DNA replication fork progression in Werner's syndrome. Aging Cell 1:30-39. doi:10.1046/j. 1474-9728.2002.00002.x
Rodriguez-Lopez AM, Whitby MC, Borer CM, Bachler MA, Cox LS (2007) Correction of proliferation and drug sensitivity defects in the progeroid Werner's syndrome by Holliday junction resolution. Rejuvenation Res 10:27-40. doi:10.1089/rej.2006.0503

Rotman G, Shiloh Y (1997) Ataxia-telangiectasia: is ATM a sensor of oxidative damage and stress? Bioessays 19: 911-917. doi:10.1002/bies.950191011

Rotman G, Shiloh Y (1998) ATM: from gene to function. Hum Mol Genet 7:1555-1563. doi:10.1093/hmg/7.10.1555

Rubin H (2002) The disparity between human cell senescence in vitro and lifelong replication in vivo. Nat Biotechnol 20:675-681. doi:10.1038/nbt0702-675

Saklatvala J (2004) The p38 MAP kinase pathway as a therapeutic target in inflammatory disease. Curr Opin Pharmacol 4:372-377. doi:10.1016/j.coph.2004.03.009

Savitsky K, Bar-Shira A, Gilad S, Rotman G, Ziv Y, Vanagaite L, Tagle DA, Smith S, Uziel T, Sfez S, Ashkenazi M, Pecker I, Frydman M, Harnik R, Patanjali SR, Simmons A, Clines GA, Sartiel A, Gatti RA, Chessa L, Sanal O, Lavin MF, Jaspers NG, Taylor AM, Arlett CF, Miki T, Weissman SM, Lovett M, Collins FS, Shiloh Y (1995) A single ataxia telangiectasia gene with a product similar to PI-3 kinase. Science 268:1749-1753. doi:10.1126/science. 7792600

Schulz VP, Zakian VA, Ogburn CE, McKay J, Jarzebowicz AA, Edland SD, Martin GM (1996) Accelerated loss of telomeric repeats may not explain accelerated replicative decline of Werner syndrome cells. Hum Genet 97:750754. doi:10.1007/BF02346184

Shay JW, Wright WE (2000) Hayflick, his limit, and cellular ageing. Nat Rev Mol Cell Biol 1:72-76. doi:10.1038/ 35036093

Shiloh Y (1997) Ataxia-telangiectasia and the Nijmegen breakage syndrome: related disorders but genes apart. Annu Rev Genet 31:635-662. doi:10.1146/annurev.genet.31.1.635

Shiloh Y (2003) ATM and related protein kinases: safeguarding genome integrity. Nat Rev Cancer 3:155-168. doi: 10.1038/nrc1011

Shiloh Y, Tabor E, Becker Y (1982) Colony-forming ability of ataxia-telangiectasia skin fibroblasts is an indicator of their early senescence and increased demand for growth factors. Exp Cell Res 140:191-199. doi:10.1016/00144827(82)90169-0

Tchirkov A, Lansdorp PM (2003) Role of oxidative stress in telomere shortening in cultured fibroblasts from normal individuals and patients with ataxia-telangiectasia. Hum Mol Genet 12:227-232. doi:10.1093/hmg/ddg023

Tollefsbol TO, Cohen HJ (1984) Werner's syndrome: an underdiagnosed disorder resembling premature aging. Age (Omaha) 7:75-88. doi:10.1007/BF02432205

Vaziri H, West MD, Allsopp RC, Davison TS, Wu YS, Arrowsmith CH, Poirier GG, Benchimol S (1997) ATMdependent telomere loss in aging human diploid fibroblasts and DNA damage lead to the post-translational activation of 553 protein involving poly(ADP-ribose) polymerase. EMBO J 16:6018-6033. doi:10.1093/emboj/ 16.19.6018

Verdun RE, Karlseder J (2006) The DNA damage machinery and homologous recombination pathway act 
consecutively to protect human telomeres. Cell 127:709720. doi:10.1016/j.cell.2006.09.034

Wang W, Chen JX, Liao R, Deng Q, Zhou JJ, Huang S, Sun P (2002) Sequential activation of the MEK-extracellular signal-regulated kinase and MKK3/6-p38 mitogen-activated protein kinase pathways mediates oncogenic ras-induced premature senescence. Mol Cell Biol 22:3389-3403. doi:10.1128/MCB.22.10.3389-3403.2002

Wong KK, Maser RS, Bachoo RM, Menon J, Carrasco DR, Gu Y, Alt FW, DePinho RA (2003) Telomere dysfunction and ATM deficiency compromises organ homeostasis and accelerates ageing. Nature 421:643-648. doi:10.1038/ nature 01385
Wood LD, Halvorsen TL, Dhar S, Baur JA, Pandita RK, Wright WE, Hande MP, Calaf G, Hei TK, Levine F, Shay JW, Wang JJ, Pandita TK (2001) Characterization of ataxia telangiectasia fibroblasts with extended life-span through telomerase expression. Oncogene 20:278-288. doi:10.1038/sj.onc. 1204072

Xia SJ, Shammas MA, Shmookler Reis RJ (1996) Reduced telomere length in ataxia-telangiectasia fibroblasts. Mutat Res 364:1-11

Yokote K, Hara K, Mori S, Kadowaki T, Saito Y, Goto M (2004) Dysadipocytokinemia in Werner syndrome and its recovery by treatment with pioglitazone. Diabetes Care 27:2562-2563. doi:10.2337/diacare.27.10.2562 